\title{
Fuzzy Logic Based Industrial Control System Design
}

\author{
Abdul Latif ${ }^{1}$, Rahmat Jalaluddin ${ }^{1}$, Susilo Ari Wibowo ${ }^{1 *}$ \\ ${ }^{1}$ Sekolah vokasi Electrical Engineering Department at Universitas Muhammadiyah Yogyakarta, \\ Indonesia. \\ *ari_susilo_wibowo@umy.ac.id
}

\begin{abstract}
Fuzzy logic controller is an alternative modern control system that is easy because it does not need to look for a mathematical model of a system, but still effective because it has a stable response. The training module that has been designed using a DC servo motor and heater is controlled by an 89S52 microcontroller and ane nethod of regulation used is fuzzy logic with a supervisory system using MN softw re. The system created is a minimal system from SCADA because there is only on $P r$ that is a data client. Fuzzy logic is designed to have two inputs (Err an $\Delta$ Err) and one output ( $\Delta$ ton). Each membership function has 5 labels. Here used 5 fuzzy if-then rules consisting of 9 main rules, 10 additional rules and 6 surplemen $r$ rules. While the fuzzy logic process consists of fuzzyfication, evaluation 1 es, and defuzzyfication. The motor driver (motor driver) uses a PWM system (pulse width nodulation) and the heater driver uses a proportional power control system. Innyt point setting is done through the SCADA software that is sent to the microcontrol er via the computer's RS232 serial port. The system response testing is carried out on a umbe of setting point variations and load variations. From the data obtained shows that me system response is quite fast in pursuing the setting point value both in ais variations, namely the load and setting point. Fuzzy logic is one of the redundant fault tolerant control systems, which means the fuzzy logic controller can sti1 ${ }^{1}$ work $\mathrm{w}$ h a reduction in some rules, or if there are small errors in programming, whov any significant changes.
\end{abstract}

Keywords:- Scada, fuzzy, serial, rt, RS232, DC Servo, microcontroller

\section{Introduction}

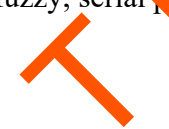

Control systems aro $r$ ceded to obtain high dynamical performance and more complex systems. Con ent onal PID is effective enough to correct error systems, but cannot be used for many parame $s$ and systems that are not linear. Efforts to find systems that are able to provide data acq isition of a process parameter in real time with a minimum error-system (error and error rate) continue to be developed. One of them is controlling technique by using Fuzzy Logic Controller (FLC) application [1]-[4]. It is suspected that the performance of the FLC with the SCADA system has many advantages when compared to the classical control system (PID). Because of some of the above analysis it is necessary to make a module to prove, analyze, and implement a distributed control system on the network using Fuzzy Logic Controller (FLC) [5]-[8].

The problems to be resolved through this proposed research are: Modeling a SCADA system that is user friendly with students and lecturers. Design of the autotuning heating process system in an effort to stabilize the process temperature. FAM (Fuzzy Association Map) design for temperature controller and water level controller. Self-detection and resolution (autosolving) of disturbances (disturbance) contained in the plant and the target system. Data link / communication techniques used to communicate between plants and 